\title{
Intrarenal Blood Flow in Children with Normal Kidneys and Congenital Heart Disease: Changes Attributable to Angiography
}

\author{
Alan B. Gruskin, [66] Vigtor H. Auerbach, and Iain F. S. Black \\ St. Christopher's Hospital for Children and Department of Pediatrics, Temple University School \\ of Medicine, Philadelphia, Pennsylvania, USA
}

\section{Extract}

Thirty ${ }^{133} \mathrm{Xe}$ determinations of renal blood flow were made in 20 children ranging in age from $16 / 12$ to $10 \% 12$ years. In six normal kidneys average blood flows to the outer and inner cortex were 374 and $44 \mathrm{ml} / \mathrm{min} / 100 \mathrm{~g}$, respectively. Mean fractional flows to these areas were 84 and $15 \mathrm{ml} / \mathrm{min} / 100 \mathrm{~g}$, respectively. In nine children with congenital heart disease (CHD) who were not in congestive heart failure and who were evaluated before angiography, a defect in outer cortical flow was demonstrated. Average blood flows to the outer and inner cortex were $250 \mathrm{ml} / \mathrm{min} / 100 \mathrm{~g}(P 0.0005)$ and $27 \mathrm{ml} / \mathrm{min} / 100 \mathrm{~g}(P 0.22)$. Mean fractional flows were $76 \%(P 0.03)$ and $24 \%$ $(P 0.015)$, respectively.

After cardiac angiography, a decrease in outer corical flow occurred. The second flow study was performed 8-30 min after injection of contrast media (Hypaque-M, $75 \%$ ) in amounts which ranged from 1.2 to $3.5 \mathrm{ml} / \mathrm{kg}$ body wt. After angiography, blood flows to the outer and inner cortex were $186 \mathrm{ml} / \mathrm{min} / 100 \mathrm{~g}(P 0.001)$ and $24.5 \mathrm{ml} / \mathrm{min} / 100 \mathrm{~g}(P$ 0.68). Average fractional flow to the outer, $74 \%$ and inner, $26 \%$ cortex, did not change $(P 0.71)$.

\section{Speculation}

Kidneys of children with CHD have decreased outer cortical flow, which may result in increased renal renin production. Therefore, a child with CHD may suffer the long term consequences of hyperreninemia. Furthermore, the balance of any metabolic system whose metabolic pathways involve the outer cortex may be altered and hemodynamic response to stressful clinical situations may be greater in the kidneys of children.

\section{Introduction}

Although information of major importance relative to renal blood flow (RBF) has been obtained using the radionucleide of the inert gas, xenon $\left({ }^{133} \mathrm{Xe}\right)$, in animals and in human adult subjects, this technique has not been used previously to investigate problems specifically related to pediatrics. The RBF is determined by injecting a bolus of ${ }^{133} \mathrm{Xe}$ into the renal artery and monitoring the rate of disappearance of the isotope by means of external counting devices placed over the kidney. Graphic analysis of the resultant data provides information relative to both the rate of nutrient flow and the fraction of total flow which perfuses the outer and inner cortical regions of the kidney. That the ${ }^{133} \mathrm{Xe}$ technique provides useful hemodynamic data in 
humans has been shown by comparison of angiographic findings $[25,48]$ or sequential $\gamma$ camera pictures [3] with information derived by graphic analysis of the washout curve.

Evaluation of renal hemodynamics by the ${ }^{133} \mathrm{Xe}$ method offers a number of technical and physiologic advantages over other clinical techniques available to measure intrarenal blood flow patterns. Technically, neither renal vein blood nor urine needs to be collected in contrast to the dye-dilution or $p$-aminohippurate clearance $\left(\mathrm{C}_{\mathrm{PAF}}\right)$ renal extraction techniques [5]. Only an end-hole catheter needs to be inserted into the renal artery and can easily be accomplished during aortography when the femoral artery is the site of entry into the arterial system. Because pertinent information can be obtained in less than $10 \mathrm{~min}$, prolonged patient cooperation is not required. Physiologically, the ${ }^{133} \mathrm{Xe}$ technique is the only clinically available method capable of providing data relating to intracortical blood flow patterns. Moreover, the units of measurement of flow, in milliliters per minute per 100 $\mathrm{g}$ [54], and fraction of total flow, as a percentage [54], are independent of body size. This permits direct comparison of data obtained in children of various ages.

Previous studies have found abnormalities in effective renal plasma flow in children with congenital heart disease $[24,41,45,46]$, and found that medullary necrosis in infants and changes in $\mathrm{C}_{\mathrm{PAF}}$ in newly born piglets may occur after administration of angiographic media [23]; accordingly, investigations relative to these problems were performed. In addition, measurements of RBF were obtained in six kidneys judged to be normal. This study reports the results of $30{ }^{133} \mathrm{Xe}$ washout curves performed in 20 children. The data obtained demonstrate that abnormalities in outer cortical blood flow occur in CHD, and that significant decreases in RBF may occur after angiography in children.

\section{Materials and Methods}

The nature of the studies to be performed, the significance of the administration of radionucleides, and the risks involved in catheterizing the renal artery were explained to the parents of each child and informed consent obtained. The parents were advised that RBF would be determined only if arterial catheterization were part of the cardiac catheterization. The computed quantity of $\gamma$ radiation to the whole body was less than 0.5 millirads $/ \mathrm{mCi}{ }^{133} \mathrm{Xe}$ administered, which can be compared with an average whole body dose of 90 millirads for an IVP. No complications occurred which could be attributed to the performance of the xenon washout curve.

Pertinent clinical data are provided in Table I. The children received their usual diets until 6-8 hr before catheterization. The clinical status of the kidneys permits their division into four groups: group $I$, kidneys considered to be normal which were studied before angiography; group II, kidneys considered to be normal which were studied only after angiography; group III, kidneys in children with CHD evaluated before angiography; and group $I V$, kidneys in children with CHD evaluated after angiography.

The washout curves calculated before administration of contrast medium were performed after completing measurements of oxygen saturation and pressures in the chambers on the right side of the heart and in the pulmonary circulation and before similar measurements of the left-sided cardiac chambers. These curves were monitored for $5-6$ min. The postangiographic studies were performed 8-30 min after injecting the contrast material and were monitored for 30 min. Table I records the total dose of contrast medium administered and the time interval after the last injection of angiographic media to the start of the flow study of the nine patients studied twice. In the remaining children, only the quantities of contrast media used in performing the angiograms were recorded. Although precise time intervals between the last angiogram and the xenon study were not recorded in the initial studies, patients 15-20, the time intervals involved were similar to those of the other studies. Hypaque-M $75 \%$ (sodium and meglumine diatrizoate) was given to the patients with CHD. Hypaque $50 \%$ (sodium diatrizoate) was given to the patients without CHD.

The method used to determine RBF and its intrarenal distribution was a modification of the krypton method originally developed in dogs [54]. A no. 5 endhold catheter was inserted through a purse-string arteriotomy and fluoroscopically guided into the renal artery. Initially, cardiac catheters were used, but later, special renal artery catheters were used. After positioning the catheter in the renal artery, $100 \mu \mathrm{Ci}{ }^{133} \mathrm{Xe}$ dissolved in $0.9 \% \mathrm{NaCl}$ solution $(0.1-0.4 \mathrm{ml})$ were rapidly injected through one side of a three-way stopcock and followed by a 2-ml $0.9 \% \mathrm{NaCl}$ flush through another side of the stopcock. The catheter was immediately withdrawn into the descending aorta out of the field of the radiation detection probe.

Three lines of evidence suggest that the injected ${ }^{133} \mathrm{Xe}$ entered only the renal circulation. First, the re- 
Table I. Clinical data ${ }^{1}$

\begin{tabular}{|c|c|c|c|c|c|c|c|}
\hline Patient & Age, yr & Height, $\mathrm{cm}$ & Weight, kg & $\begin{array}{l}\text { Hemoglobin } \\
\mathrm{g} / \mathrm{dl}\end{array}$ & Diagnosis & $\begin{array}{l}\text { Contrast } \\
\text { medium given, } \\
\mathrm{ml} / \mathrm{kg}\end{array}$ & $\begin{array}{l}\text { Time to flow } \\
\text { study after } \\
\text { angiography } \\
\text { min }\end{array}$ \\
\hline 1 & $42 / 12$ & 94 & 13.4 & 10.8 & Suspected renal mass & $1.1^{2}$ & 17 \\
\hline 2 & $86 / 12$ & 126.4 & 26.4 & 14 & Unilateral hematuria & & \\
\hline 3 & $76 / 12$ & 119.4 & 22.6 & 12 & Unilateral renal hypertension & & \\
\hline 4 & $97 / 12$ & 120.7 & 24.3 & 12.2 & Unilateral hematuria & $1.6^{2}$ & 22 \\
\hline 5 & 41112 & 101.6 & 15.6 & 12.4 & Left renal vascular hypertension & $0.8^{2}$ & \\
\hline 6 & $45 / 12$ & 96.5 & 11.8 & 12.7 & PDA, 2nd block, AI, VSD & 3.5 & 10 \\
\hline 7 & $54 / 12$ & 95.3 & 12.7 & 12.5 & MS, VSD & 3.2 & 30 \\
\hline 8 & $65 / 12$ & 118.1 & 20.8 & 10.9 & Coronary artery to $\mathrm{RV}$ fistula & 2.6 & 22 \\
\hline 9 & $35 / 12$ & 97.8 & 12.7 & 10.7 & VSD & 3.0 & 10 \\
\hline 10 & $53 / 12$ & 111.1 & 18.6 & 12.7 & Pulmonary artery banding, closed VSD & 2.6 & 14 \\
\hline 11 & $57 / 12$ & 125.1 & 23.1 & 12.8 & VSD, PS & 2.4 & 27 \\
\hline 12 & $15 / 12$ & 88.9 & 13.1 & 11.3 & Coarctation aorta & 1.2 & 16 \\
\hline 13 & $109 / 12$ & 120 & 24.5 & 19.9 & $A-V$ canal, $R-L$ shunt & 1.84 & 9 \\
\hline 14 & $86 / 12$ & 130.2 & 26.8 & 13.4 & Pulmonary stenosis & 2.1 & 8 \\
\hline 15 & $76 / 12$ & 118.7 & 19.1 & 13 & ASD, MI, AI, VSD, postsurgical repair & $3.0^{2}$ & \\
\hline 16 & 7 & 113.7 & 17.5 & 14.8 & $\mathrm{AS}, \mathrm{VSD}$ & $1.3^{2}$ & \\
\hline 17 & $29 / 12$ & 88.9 & 11.4 & 11.9 & VSD & $2.8^{2}$ & \\
\hline 18 & $61 \% 12$ & 109.2 & 17.7 & 11.6 & AS & $1.7^{2}$ & \\
\hline 19 & $37 / 12$ & 92.7 & 11.4 & 12.6 & VSD, ASD & $2.3^{2}$ & \\
\hline 20 & $71 / 12$ & 111.8 & 17.5 & 12.4 & Post-TF correction & $2.4^{2}$ & \\
\hline
\end{tabular}

1 PDA : patent ductus arteriosus, AI : aortic insufficiency, VSD : ventricular septal defect, MS : mitral stenosis, RV : right ventricular, PS : pulmonary stenosis, A-V : arteriovenous, R-L : right-left, ASD : atrial septal defect, MI : mitral insufficiency, AS : aortic stenosis TF : tetralogy of Fallot.

2 These quantities of contrast medium are less than the total quantity by the amount of medium used in the various hand injections to localize the position of the catheter.

sultant washout curve looked like a ${ }^{133} \mathrm{Xe}$ washout curve. Second, because injected xenon leaves the renal vein and is almost entirely excreted by the lungs on its first circulation, any ${ }^{133} \mathrm{Xe}$ which fails to enter the renal artery will travel down the aorta into the leg and be detectable there. Although we did not monitor the leg opposite the arteriotomy in every study, we did so in a number of patients, and in no instance were we able to detect any radioactivity within the initial 5-10 sec after injecting ${ }^{133} \mathrm{Xe}$. Third, in those patients evaluated after angiography, $0.25-0.5 \mathrm{ml}$ contrast medium was injected into the renal artery and monitored on videotape in order to verify the position of the catheter.

Monitoring of the rate of washout of ${ }^{133} \mathrm{Xe}$ was accomplished by placing a 2-inch sodium iodide crystal, which was recessed 3 inches into a conical lead collimator, 1-2 inches above the anterior abdominal wall and aimed toward the kidney and away from the lung. The probe was powered by a Packard Selectronic model 45-22 analyzer [60]. The washout data were continuously recorded on a Cipher model $100 \times 409$ track tape recorder [61]. The 9 tracks were electroni- cally modified by Mr. John Whitney of the Cipher Data Products Corporation [61] so that the 1st, 4th, 7 th, etc., radioactive counts were recorded on track 1 ; the 2nd, 5th, 8th, etc., on track 2; and the 3rd, 6th, 9th, etc., on track 3. Tracks 4, 5, and 6 and 7, 8, and 9 were modified in a similar fashion. Each group of three tracks, i.e., channels $I, I I$, or III was now capable of recording in a linear fashion $50,000 \pm 0.5 \%$ (SD) cps generated from one probe. Standard 9-track Ampex [62] magnetic tapes were used. Repeated playback of the tape demonstrated that the tape stretched less than $0.003 \%$.

The resultant data were subsequently fed at 1-sec intervals into consecutive channels of a 4096-channel Hewlett-Packard [63] model 5401 multichannel analyzer. Each discrete channel was then used as a memory unit for a finite interval of the washout curve. The entire curve was displayed on the cathode ray tube of the multichannel analyzer, and the initial rapid downward defection of the curve identified and designated as time zero.

The stored data were then manipulated by a series of programs written for the Hewlett-Packard 9100A 
computer calculator and model 9101A extended memory which was in direct two-way communication with the multichannel analyzer through a Hewlett-Packard model $2570 \mathrm{~A}$ coupler controller. Initially, the background count rate was subtracted. Next, a graphic plot of the natural logarithm of the count rate was plotted against time and printed out graphically on the Hewlett-Packard X-Y plotter model 9125A.

The washout curves were monitored for either 5-6 min or $30 \mathrm{~min}$. The resulting data were analyzed subsequently by one or more of three procedures, henceforth referred to as the $30-\mathrm{min}, 300-\mathrm{sec}$, and 750 -sec analytic methods. Thirty-minute curves were analyzed after being plotted on the X-Y plotter by initially determining the terminal straight component of the curve by visual inspection. The memory channels in the multichannel analyzer which corresponded to these data points were identified. A least squares regression line was computed automatically using the stored data in these channels, and the data points beyond \pm 1.75 so from the line were eliminated from the appropriate memory channels. A second least squares line was then computed and drawn by the plotter. The values of the zero time intercept and slope per channel [54], i.e., per second, were displayed on the digital printer of the unit. The computed straight line was then subtracted point by point from the original curve and a new curve plotted and held in memory. This process was repeated sequentially until no further components could be identified. With one exception, three components were identified in the 30 -

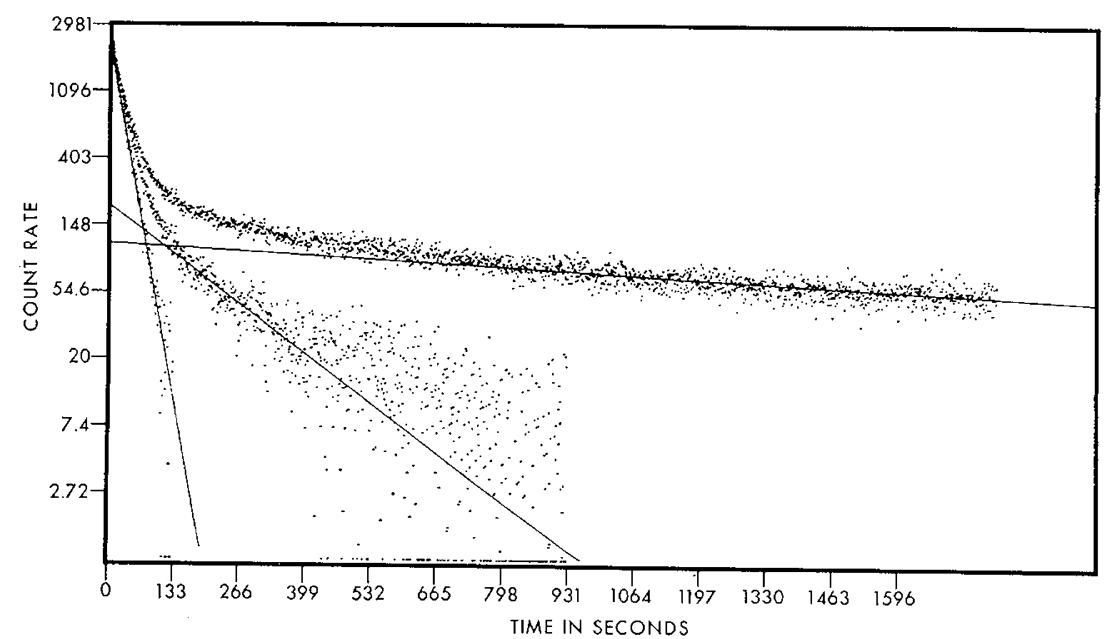

Fig. 1. Thirty-minute washout curve. The logarithm of the count rate per second is plotted against time in seconds. The terminal straightline portion of the curve is identified by visual inspection and a straight line computed and drawn from time zero. This line is then subt tracted point by point from the original curve and a new curve obtained. The process is repeated sequentially. An original curve as drawn on the $\mathrm{X}-\mathrm{Y}$ plotter is shown. The straight lines have been darkened to permit reproduction.

Table II. Analysis of washout curves by $30-\mathrm{min}, 300-\mathrm{sec}$, and $750-\mathrm{sec}$ methods ${ }^{1}$

\begin{tabular}{|c|c|c|c|c|c|c|c|}
\hline \multirow{2}{*}{ Method } & \multicolumn{4}{|c|}{$300 \mathrm{Sec}$} & \multicolumn{3}{|c|}{$750 \mathrm{Sec}$} \\
\hline & $\mathrm{n}$ & $\mathrm{r}$ & $\mathrm{t}$ & $P$ & $\mathrm{r}$ & $\mathrm{t}$ & $P$ \\
\hline Flow outer cortex, component I & 14 & 0.99 & 19.8 & $<0.0001$ & 0.92 & 8.37 & $<0.0001$ \\
\hline Flow inner cortex, component II & 14 & -0.104 & 0.36 & 0.72 & 0.54 & 2.23 & 0.046 \\
\hline Flow outer cortex, component $1, \%$ & 14 & 0.61 & 2.67 & 0.02 & 0.95 & 10.5 & $<0.0001$ \\
\hline Flow inner cortex, component $I I, \%$ & 14 & 0.58 & 2.49 & 0.03 & 0.96 & 11.8 & $<0.0001$ \\
\hline
\end{tabular}

${ }^{1}$ Fourteen washout curves, some of which are not included in this report, were analyzed by the 30 -min, 300-sec, and 750-sec analytic methods. The results for components $I$ and $I I$, i.e., outer and inner cortex of the 300 - and 750 -sec methods were compared with similar data obtained from 30-min curves. Identical data from the original washout curve after background subtraction was held in memory in the multichannel analyzer and analyzed as described in the text. Linear regressions of the 300- or 750-sec method versus the 30-min method were computed for both flow and fractional flow of both component $I$ and $I I$. The correlation coefficients and tests of significance as shown demonstrate that the 750 -sec method provides data which correlated significantly $(P<0.05)$ with similar data derived from 30 -min analyses. Data for component II obtained by the $300-\mathrm{sec}$ analytic method does not correlate with that obtained by the 30 -min method. 
min curves. An example of a 30 -min curve is shown in Figure 1 .

In the 300 -sec method, the count rate corresponding to $300 \mathrm{sec}$ from the origin of the curve was taken as a constant value representative of the third component and subtracted from preceding count rates. The newly generated curve was then analyzed as a two-component curve in a manner similar to that described for the 30 min curve. Curves analyzed in this fashion by others $[13,38,49]$ and as shown in Table II provide data which are accurate for component $I$ only.

The 750 -sec method, which is a new approach to analyzing 300 -sec curves, consisted of starting with a 300 -sec curve. A least square regression line was fitted to the data points between 250 and $300 \mathrm{sec}$. This line was extrapolated beyond the end of the curve to obtain the count rate at $750 \mathrm{sec}$. This value was then used as a constant representative of the third component and subtracted from the original curve. The resultant curve was then analyzed as a two-component curve. Figure 2 contains a representative example of the 750 -sec method of analysis.

Fourteen curves were analyzed by all three methods. Information contained in Table II demonstrates that when the results of the 300 -sec method were compared with those obtained by the 30 -min method, the data is valid for component $I$ only. Other investigators have obtained similar results $[13,39,48]$. Because flow and fractional flow for components $I$ and $I I$, as derived from the 750-sec method, were similar to those obtained by the 30 -min method, whenever results from 5 min curves are given, only the numbers derived from the 750-sec method of analysis will be presented.

Regional flow rates per $100 \mathrm{~g}$ kidney were calculated from the slopes of each component [54]: $\mathrm{F}=(\mathrm{k} \times \lambda \times$ $100) / \rho$ where $F$ is the flow in milliliters per minute per $100 \mathrm{~g}$ of renal tissue; $\mathrm{k}$ is the slope of the component; $\lambda$ is the partition coefficient for xenon in the kidney and was assumed to be 0.7 ; and $\rho$ assumed to be 1.0, is the specific gravity of the kidney. The fraction of flow which perfuses these components was determined by adding together the count rate at time zero of each component and dividing the count rate of any given component by the total number of counts. In the 5min curves, the contribution of the third component was disregarded. In the studies performed after angiography, although 30-min curves were obtained and analyzed, the initial 5-min portion of the curve was also analyzed in order to permit comparisons to the 5-min curves obtained before angiography. Conventional graphic analysis permits separation of individual com-

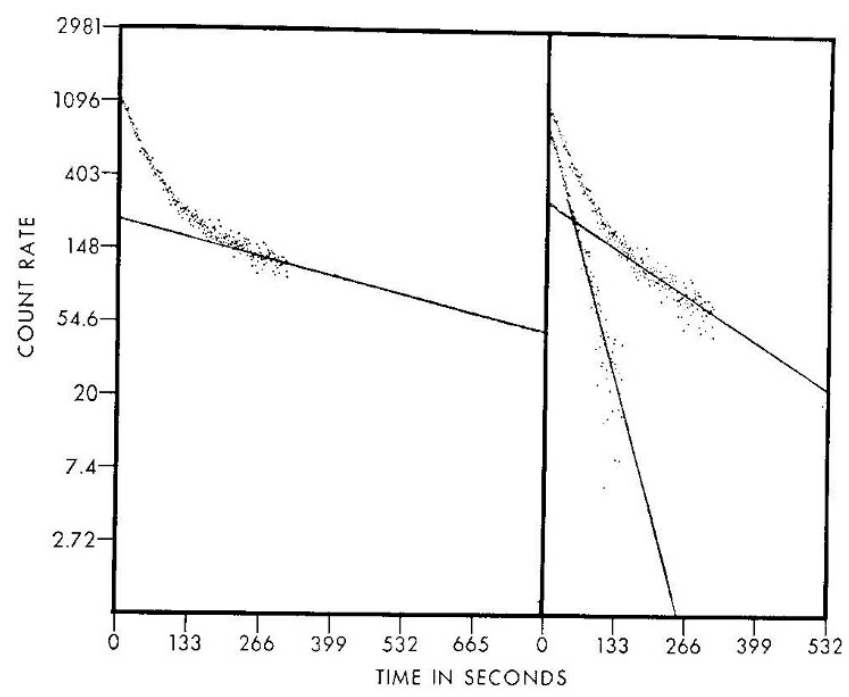

Fig. 2. Seven hundred fifty-second method of analysis. The original 5-min curve is shown on the left. A straight line was calculated using the data points between 250 and $300 \mathrm{sec}$ and the count rate corresponding in time to $750 \mathrm{sec}$ was obtained. This value was then subtracted from the original curve and the curve on the right was obtained. The resultant curve was then analyzed as a two-component curve. A curve as drawn on the $\mathrm{X}-\mathrm{Y}$ plotter is shown. The straight lines have been darkened to permit reproduction.

ponents only if the $t 1 / 2$ of the components differ by a factor of 3 [47]. Tests of significance between mean values were calculated by means of the student $t$ test The sEM follows the mean values for blood flow and fractional flow.

\section{Results}

Individual patient values for RBF and fractional flow are contained in Table III.

\section{Studies of Kidneys Considered to be Normal}

Patients 1, 2, 3, 4, and 5 underwent aortography for the purpose of evaluating primary renal disease. In each patient the normal kidney was studied. The kidney involved in the two patients being evaluated for unilateral hematuria had been identified previously by cystoscopy. Renal arteriography failed to reveal any abnormalities. In the two children being evaluated for hypertension, the involved kidney was shown in one to have perirenal bleeding related to trauma and in the other to have fibromuscular dysplasia. The child suspected of having a renal mass was shown to have normal kidneys bilaterally and both kidneys were studied.

As the data generated in these children before or 
Table III. Discrete flow data for individual patients derived by $30-\mathrm{min}$ and 750 -sec method of graphic analysis

\begin{tabular}{|c|c|c|c|c|c|c|c|c|c|c|}
\hline & \multicolumn{6}{|c|}{ 30-Min analysis } & \multicolumn{4}{|c|}{$750-\mathrm{Sec}$ analysis } \\
\hline & \multicolumn{3}{|c|}{ Flow, $\mathrm{ml} / \mathrm{min} / 100 \mathrm{~g}$} & \multicolumn{3}{|c|}{ Flow, \% } & \multicolumn{2}{|c|}{ Flow, $\mathrm{ml} / \mathrm{min} / 100 \mathrm{~g}$} & \multicolumn{2}{|c|}{ Flow, \% } \\
\hline & I & II & III & $\mathrm{I}$ & II & III & I & II & I & II \\
\hline 1. $\operatorname{Pre}^{1}$ & & & & & & & 401.1 & 27.3 & 84.8 & 15.2 \\
\hline 1a. Pre & & & & & & & 429.9 & 21.1 & 84.8 & 15.2 \\
\hline 2. $\operatorname{Post}^{2}$ & 341.96 & 61.72 & 16.82 & 86.95 & 6.97 & 9.74 & & & & \\
\hline 3. Post & 370.5 & 105.3 & 24.3 & 74.64 & 22.6 & 2.76 & & & & \\
\hline 4. Pre & & & & & & & 324.6 & 23.2 & 87.28 & 12.72 \\
\hline 5. Pre & & & & & & & 376.7 & 25 & 85.06 & 14.94 \\
\hline 6. Pre & & & & & & & 267.6 & 23.5 & 69.61 & 30.39 \\
\hline Post & 149.6 & 25.2 & 1.6 & 72.56 & 18.91 & 8.53 & 162.9 & 19.74 & 79.01 & 20.99 \\
\hline 7. Pre & & & & & & & 273.7 & 27.14 & 73.77 & 26.23 \\
\hline Post & 169.9 & 27 & 1.7 & 73.39 & 18.01 & 8.6 & 190.8 & 22.9 & 69.03 & 30.97 \\
\hline 8. Pre & & & & & & & 252.9 & 31.12 & 80.96 & 19.54 \\
\hline Post & 225.4 & 25.7 & 1.1 & 90.29 & 5.6 & 4.11 & 238.9 & 18.96 & 89.69 & 10.31 \\
\hline 9. Pre & & & & & & & 290.8 & 64.2 & 67.85 & 31.01 \\
\hline Post & 167 & 23.1 & 1.7 & 87.71 & 7.87 & 4.42 & 168.6 & 15.71 & 91.69 & 8.31 \\
\hline 10. Pre & & & & & & & 289.7 & 12.21 & 89.87 & 10.13 \\
\hline Post & 297.2 & 24.7 & 0.6 & 87.96 & 7.54 & 4.50 & 252.5 & 36.1 & 90.05 & 9.95 \\
\hline 11. Pre & & & & & & & 195.8 & 29.2 & 70.64 & 29.36 \\
\hline Post & 174.2 & 39.1 & 1.3 & 69.73 & 26.22 & 4.05 & 180.8 & 35.2 & 70.03 & 29.97 \\
\hline 12. Pre & & & & & & & 255.8 & 28.95 & 82.38 & 17.62 \\
\hline Post & 145.7 & 29.7 & 1.4 & 54.63 & 35.66 & 9.71 & 161.5 & 26.54 & 52.73 & 47.27 \\
\hline 13. Pre & & & & & & & 172.9 & 13.0 & 76.21 & 23.74 \\
\hline Post & & & & & & & 119.0 & 14.9 & 71.9 & 28.1 \\
\hline 14. Pre & & & & & & & 252.5 & 16.9 & 69.5 & 30.5 \\
\hline Post & & & & & & & 200.6 & 30.2 & 47.9 & 52.1 \\
\hline 15. Post & 274.9 & 72.1 & 20.7 & 80.95 & 14.91 & 4.14 & & & & \\
\hline 16. Post & 147.6 & 25.9 & 0.09 & 64.08 & 29.57 & 6.36 & & & & \\
\hline 17. Post & 184.8 & 21.7 & 1.3 & 78.84 & 14.88 & 6.27 & & & & \\
\hline 18. Post & 307.2 & 35.0 & 0.9 & 80.26 & 15.89 & 3.86 & & & & \\
\hline 19. Post & 195.2 & 29.3 & 1.3 & 79.34 & 23.38 & 1.27 & & & & \\
\hline 20. Post & 278.9 & 57.5 & 6.8 & 73.47 & 16.79 & 9.74 & & & & \\
\hline
\end{tabular}

1 Pre: preangiocardiogram.

2 Post: postangiocardiogram.

after angiography (clinical groups $I$ and $I I$ ) revealed similar values and also were within the known range of values reported previously in normal adults, they will be considered as a single group. The average flow rates to the outer and inner cortex were $374 \pm 16$ and $44 \pm 14 \mathrm{ml} / \mathrm{min} / 100 \mathrm{~g}$. The range of values for flow to the outer cortex was 325 to $430 \mathrm{ml} / \mathrm{min} / 100 \mathrm{~g}$. Fractional flow to the same regions was $83.9 \pm 1.9 \%$ and $14.6 \pm 4 \%$, respectively; the remaining $1.5 \%$ belonged to the third component as determined by the $30-\mathrm{min}$ method of analysis.

\section{Studies of Kidneys after Angiography in Children with CHD}

Patients 6-20 had determinations of renal blood flow performed at the conclusion of their cardiac catheterization. Thirty-minute curves were obtained in 13 children, patients 6-12 and 15-20. One curve had four components, the others contained only three components. Patients 15 through 20 were the initial group of patients whose kidney function was evaluated by xenon washout curves. When it became evident that outer cortical flows were low, we started performing our xenon studies before angiography. As might be expected, the data obtained in this group did not differ from those data from patients 6-12 who were studied subsequently, and the two groups can be considered together.

Graphic analyses of these 30 -min curves show that the blood flow to the outer cortex averaged $209 \pm 17$ $\mathrm{ml} / \mathrm{min} / 100 \mathrm{~g}$ and $33.5 \pm 4 \mathrm{ml} / \mathrm{min} / 100 \mathrm{~g}$ to the inner cortex. Fractional flows to the outer and inner cortical regions were $76 \pm 3 \%$ and $18 \pm 2.5$, respectively. As the physiologic significance of the data generated from component III is questionable, the results for this component were not averaged. 
Table IV. Mean \pm SEM for renal blood flow and fractional flow in children with normal kidneys and congenital heart disease (CHD) ${ }^{1}$

\begin{tabular}{|c|c|c|c|c|c|}
\hline & $\underset{(\mathrm{n}=6)}{\text { Group } A, \text { normal subjects }}$ & $\begin{array}{c}\text { Group } B, \text { CHD }(\mathrm{n}=9), \\
\text { preangiocardiogram }\end{array}$ & $\begin{array}{c}\text { Group } C, \text { CHD }(\mathrm{n}=9), \\
\text { postangiocardiogram }\end{array}$ & $P$ values, $A / B$ & $P$ values, $B / C$ \\
\hline \multicolumn{6}{|c|}{ Flow, $\mathrm{ml} / \mathrm{min} / 100 \mathrm{gm}$} \\
\hline Component I & $374.1 \pm 15.6$ & $250.2 \pm 13.5$ & $186.2 \pm 13.6$ & 0.0005 & 0.001 \\
\hline Component II & $43.9 \pm 13.8$ & $27.4 \pm 5.2$ & $24.5 \pm 2.7$ & 0.22 & 0.68 \\
\hline \multicolumn{6}{|c|}{ Fractional flow, $\%$} \\
\hline Component $I$ & $83.9 \pm 1.9$ & $75.6 \pm 2.5$ & $73.6 \pm 5.3$ & 0.03 & 0.71 \\
\hline Component II & $14.6 \pm 2.1$ & $24.4 \pm 2.5$ & $26.4 \pm 5.3$ & 0.015 & 0.70 \\
\hline
\end{tabular}

${ }_{1}$ Statistical comparison, $P$ values, between groups are shown in the last two columns.

Studies of Kidneys before and after Angiography in Children with CHD

Renal blood flow in patients 6-14 was measured twice. Five-minute curves were performed before angiography and both 5- and 30-min curves after angiography. The results obtained from the initial 5-min segment of the $30-\mathrm{min}$ washout curve after angiography were used to compare with the preangiographic study. The data and statistical analysis of these studies are contained in Tables III and IV.

In the studies performed before angiography, blood flow to the outer cortex using the 750 -sec method of analysis was $250 \pm 13.5 \mathrm{ml} / \mathrm{min} / 100 \mathrm{~g}$ and $27 \pm 5 \mathrm{ml} /$ $\min / 100 \mathrm{~g}$ to the inner cortex. Fractional flow was $76 \pm$ $2.5 \%$ and $24 \pm 2.5 \%$ to the outer and inner cortex, respectively.

As shown in Table IV, outer cortical flow in the children with $\mathrm{CHD}$ was significantly lower than that found in our normal control kidneys. The reduced flow was associated with a redistribution of flow from the outer to the inner cortex. The time elapsed after angiocardiography to the performance of the second xenon study ranged from 8 to $30 \mathrm{~min}$. In no study did the quantity of contrast medium injected for a given angiogram exceed $1.0 \mathrm{ml} / \mathrm{kg}$. The number of angiograms performed in an individual patient ranged from one to four.

A decrease in outer cortical flow occurred in these nine patients after angiography. Outer and inner cortical flows after angiography were $186 \pm 14$ and $24.5 \pm 3$ $\mathrm{ml} / \mathrm{min} / 100 \mathrm{~g}$. Fractional flows were $74 \pm 5 \%$ and $26 \pm$ $5 \%$, respectively. A significant change occurred in outer cortical flow. Both increases and decreases in flow to the inner cortex and in fractional flow to both the outer and inner cortex occurred. Therefore, no statistical unidirectional changes in these variables was found. The quantity of contrast medium injected was not related to the change in blood flow which occurred after angiography.

\section{Discussion}

These studies in children provide renal hemodynamic data which deal with three distinct problems which require elaboration. The discussion to follow will comment first on blood flow relating to normally functioning kidneys, then upon the site of abnormality of the defect in renal blood flow in children with CHD, and, finally, upon the effect of angiography on RBF in children.

\section{Renal Blood Flow in Normal Kidneys}

The five patients considered to have normal kidneys had values for both blood flow and fractional flow to the superficial and inner cortical regions of the kidney within the range of values reported for normal adult patients ingesting unrestricted diets. All were in the age range in which values both for glomerular filtration rate (GFR) and for renal plasma flow measured by the clearance of inulin and PAH, if expressed in terms of body surface area, are similar to adult values. Although ${ }^{133} \mathrm{Xe}$ studies were not performed in children below 2 years of age, it is known that renal plasma flow $\left(\mathrm{C}_{\mathrm{PAII}}\right)$ per gram of kidney is reduced in these children [2].

Because changes in cardiac output [37] in relation to body size after birth are not great enough to explain increases in RBF, it follows that any increase in total $\mathrm{RBF}$ with age in relation either to kidney weight or surface area must occur as a result of an increase in blood flow per gram of kidney tissue, for autopsy studies have shown that the ratio of kidney weight to body weight in the human infant after birth remains constant or decreases [44]. Once blood flow per gram of kidney reaches adult levels, further increases in total $\mathrm{RBF}$ can be expected to occur only in relation to an increase in renal mass.

These data in children, together with that in normal adults, demonstrate that once blood flow per gram 
of tissue reaches adult values, it remains constant. In addition, since the ${ }^{133} \mathrm{Xe}$ technique provides data for flow directly in units of milliliters per gram of kidney, the results provide direct support for the use of surface area correction factors in attempting to normalize data relating to renal plasma flow and probably GFR in order to compare renal function studies in children above 2 years of age to similar type studies in adult patients. Data obtained in both infant piglets [22] and puppies [29] by microsphere and/or gas washout techniques and that available dealing with cardiac output, $\mathrm{C}_{\mathrm{T} \Lambda \mathrm{H}}$, and blood pressure both in the animals and in the growing child [22], have shown that this increase in RBF with age occurs as a hemodynamic consequence of a progressive fall in total renal vascular resistance, with the principal increase in blood flow occurring in the superficial cortical regions. It is also reasonable to assume that the fraction of cardiac output which perfuses the kidney reaches adult values at the time in maturation that renal blood flow per gram of kidney obtains adult values.

\section{Renal Blood Flow in CHD}

Decreased renal plasma flow in children with both cyanotic and acyanotic CHD has been demonstrated by a number of investigators using the PAH clearance technique $[24,41,45,46]$. Although the GFR is usually normal, some patients have had reduced levels of GFR in the absence of heart failure. These abnormalities persist beyond infancy when GFR and $\mathrm{C}_{\mathrm{PAH}}$, if corrected for body surface, ought to be similar to adult values. The finding that the renal extraction of $\mathrm{PAH}$ in children with both cyanotic and acyanotic CHD is within the range reported for normal adults provides evidence that the decrease in renal plasma flow in congenital heart disease is not caused by a shift of blood flow from cortex to medulla, i.e., glomerular versus nonglomerular flow, but must reflect an abnormality in cortical flow [4.0]. That the decrease in renal plasma flow is not an artifact resulting from an increased hematocrit in patients with cyanotic heart disease is proven by the findings of a reduction in total $\mathrm{RBF}$ in these patients. The resulting increase in filtration fraction in both cyanotic and acyanotic patients with CHD suggests that an increase in cortical vascular resistance probably exists in children with CHD. Moreover, these abnormalities often persist for years after successful surgical correction of the cardiac defect $[24,46]$, although some data exist which show that $\mathrm{C}_{\mathrm{PAF}}$ may increase toward normal values after surgery.
In addition to the functional changes noted, anatomic abnormalities which consist of thickening and/ or destruction of capillary walls, dilatation of afferent arterioles, prominence of the juxtaglomerular apparatus, the occurrence of enlarged glomeruli and mesangial prominence have been described in children with CHD [50-52, 56]. Spear feels that there may be a tendency toward hyaline changes in the renal arterioles in some patients [52]. The pathogenesis of these changes remains unknown and can not be attributed to either polycythemia or hypoxia alone.

The present studies extend our knowledge of renal hemodynamics in CHD by documenting the decrease in $\mathrm{RBF}$ in individuals with $\mathrm{CHD}$ by a more direct technique than the $\mathrm{C}_{\mathrm{PAF}}$ method. With the exception of a few measurements of total RBF by means of the $\mathrm{C}_{\mathrm{P} \text { AII }}$ extraction technique in children under 2 years of age, no true measurements of RBF other than those reported here are available in children. The use of the ${ }^{133} \mathrm{Xe}$ technique by measuring $\mathrm{RBF}$ directly eliminates the possibility that the reduced $\mathrm{C}_{\mathrm{P} \Lambda \mathrm{II}}$ values reported previously might reflect invalid surface area correction factors attributable to abnormalities of growth in children with CHD [42]. The defect in blood flow has been shown to occur in the region of the outer cortex. Patient 20, evaluated before angiography, the only patient who was studied 1.5 years after corrective cardiac surgery, was shown to still have diminished outer cortical flow, and this suggests that the defect is permanent once it occurs.

Although our results are similar to those obtained by the ${ }^{133} \mathrm{Xe}$ technique in experimental heart failure $[31,32]$, as well as in some adults being treated for heart failure [18], none of our patients had ever been in failure and the left ventricular end diastolic pressure was normal in these patients. Since most of the adult patients had either aortic or mitral valve disease, it is probable that they had rheumatic heart disease and not CHD. It may be that patterns of renal blood flow are different in acquired as opposed to CHD, for both blood flow and fractional flow in some adults were within normal adult values. Although the pathophysiology of the redistribution of blood flow in congestive heart failure is not completely understood, it may be related to changes in catecholamines and effective arterial filling.

The clinical implication and pathogenesis of this defect in renal blood flow must remain speculative; however, a number of observations are of interest. Inasmuch as abnormalities in outer cortical flow have 
been correlated with changes in the renin angiotensin system $[26,55]$, it may be that with increasing age, the individual with $\mathrm{CHD}$ is at risk for developing the consequences of hyperreninemia. Indeed, plasma renin activity has been reported to be higher in children with CHD than in normal children of similar ages [53]. Unpublished studies in our own laboratory have shown similar findings [21]. Hyperreninemia associated with reduced outer cortical blood flow has been noted in patients with either essential hypertension and/or renal artery stenosis [26]. Moreover, reduced outer cortical blood flow may persist after surgical correction in children with GHD.

If it is assumed that the defect in outer cortical flow persists in children with CHD, it may be that this defect represents a failure of the normal developmental processes. The rate of maturation of the kidney is influenced by the dietary intake in the newborn period. Premature infants fed a high solute, high protein diet increase both their GFR and $\mathrm{C}_{\mathrm{PAI}}$ at a faster rate than premature infants fed a "normal" diet [16]. The kidneys of newborn rats in whom caloric intake is restricted have been shown to demonstrate both a morphologic and functional lag when compared with controls [59]. Studies of RBF in the developing kidney of the puppy have shown a reduced outer cortical flow and a greater fraction of RBF which perfuses the inner cortex in contrast to the adult kidney which has a high outer cortical flow and a large fraction of total flow perfusing the outer cortex [29]. The patterns of blood flow observed in our patients are similar to that of the infant kidney. In addition, Solomon and Capek [49] have demonstrated that the level of food intake influences the rate of increase of superficial nephron GFR in developing rats, which suggests that the availability of solute and/or calories not only influences the rate of maturation of $\mathrm{RBF}$, but its redistribution as well. It may be that unless the stimuli which result in renal maturation are operative during a critical period of growth, a permanent and irreversible defect in renal function occurs.

Chronic malnutrition [1], i.e., infantile protein caloric malnutrition and kwashiorkor, is also known to reduce renal plasma flow. Moreover, $\mathrm{C}_{\mathrm{PAH}}$ returns to normal values after malnutrition in children is treated, in contradistinction to the persistence of the defect in $\mathrm{C}_{\mathrm{PA} \text { A }}$ after surgical correction of the cardiac defect. Although many of our patients with CHD were below the 3rd percentile for height, the defect in renal blood flow was also present in the children who were of normal height. It may be that growth and renal maturation during infancy was retarded in these patients.

Another possibility which requires consideration deals with the relation of catecholamines to intrarenal blood flow patterns. Infusions of various catecholamines reduce outer cortical flow and the developing kidney has been shown to be more sensitive to a given level of circulating catecholamine than the adult kidney [30]. Although catecholamine excretion is increased in congestive heart failure [11] and might influence renal cortical flow, catecholamine excretion is normal in children with CHD [10]. Thus, it is not likely that catecholamine metabolism is causally related to the abnormality in RBF in children with $\mathrm{CHD}$ who are not in heart failure.

\section{Effect of Angiography on Kidney}

The child undergoing angiocardiography, especially the infant, may be more inclined to develop significant renal toxicity following intravascular contrast administration than the adult because of the relatively greater quantities of contrast media given to children. Toxic renal manifestations of contrast media in children include hematuria [23], hemoglobinuria [12], proteinuria [33], and both transient and permanent renal insufficiency. Renal medullary necrosis [23], a rare pediatric problem, has been reported to follow angiocardiography in a number of infants. The findings of marked decreases in $\mathrm{C}_{\mathrm{PAE}}$ after contrast administration in newly born piglets suggest that renal hemodynamic changes play a causal role in the development of medullary necrosis. In human infants, a single injection of contrast media $(1 \mathrm{ml} / \mathrm{kg})$ does not significantly affect creatinine clearance [43].

Although contrast media are intended only for diagnostic use and ought ideally to exhibit neither pharmacologic nor toxic effects, in actual practice they exert both effects [20]. Modern angiographic media are excreted through the kidney by the process of glomerular filtration and act as nonreabsorbable solutes. A nonreabsorbable solute, if given in sufficiently large quantities, may induce an osmotic diuresis and produce clinical dehydration. In a child with CHD without fluid intake for a period of time before cardiac catheterization, who may already have abnormal renal function, the level of renal function may be further compromised by worsening the state of hydration.

In considering the effect of contrast medium on renal function in patients undergoing cardiac angiog- 
raphy, both the effect of contrast medium on cardiac function with it secondary effect on renal function and the effect of angiography media directly on the kidney itself have to be considered. One type of response to administration of contrast medium into cardiac chambers or into the aorta is one of an increase in cardiac output, a rise in heart rate and stroke volume, and an elevation in blood pressure [4]. These changes probably reflect changes in blood volume rather than a direct effect on the myocardium. The small quantities of contrast used in coronary artery angiography do not produce similar hemodynamic changes [34]. Conversely, decreases in myocardial contractility, elevations of left atrial pressure, and both pulmonary and systemic hypotension have occurred after contrast administration [19, 38]. Generally, these effects resolve within a few minutes. Systemic hypotension after angiocardiography did not occur in any of the patients evaluated in these studies. Unless the volume expansion results in the development of heart failure, it would appear that any drop in RBF after cardiac angiography is not related to changing cardiac hemodynamics but to a more direct effect of contrast on the renal circulation, although acute changes in left atrial pressure may effect renal hemodynamics.

In regard to the effect of contrast media on renal hemodynamics, three different responses of the renal vascular bed have been reported in animals [6]. These include vasodilatation, vasoconstriction, and a biphasic response which consists of a transient vasodilatation followed by a period of vasoconstriction. Some of these differences may reflect differences in techniques of the time period examined. Apparently, only the kidney and lung [17] contain vasculature which responds to the administration of hypertonic solutions with vasoconstriction, for the carotid, femoral, and myocardial circulation respond by vasodilatation [6].

In a series of studies using an electromagnetic flow meter, the drop in renal blood flow after contrast administration was shown not to be related to changes in catecholamine levels, for injection of contrast medium still induced vasoconstriction when RBF was reduced either by hemorrhage, which increases catecholamine release, or by norepinephrine infusions [6, 7]. The vasoconstrictor effect of contrast medium did not occur after continuous angiotensin infusion. It was suggested that although the kidney generally responds to acute infusions of angiotensin by decreasing outer cortical flow $[6,8,9,28]$, once angiotensin tachyphylaxis occurs [6], the kidney becomes insensitive to continuous renin release.
Inasmuch as a similar response occurs after hypertonic saline solution injection, it is the hypertonicity of contrast medium and not its chemical composition which produces vasoconstriction. A recent study in dogs demonstrated that hypertonic solutions of sodium chloride, dextrose, or urea infused into the renal artery increased renal renin release threefold [58]. Presumably, local renin release is increased and intrarenal vasoconstriction occurs. Angiograms obtained both before and after injection of contrast medium show changes confined to the outer cortical region of the kidney [6]. This suggests that the contrast medium affects arteries less than $250 \mu \mathrm{m}$ in diameter, which are known to respond to angiotensin.

The changes in RBF found in these studies are different from those found after renal angiography in normal adults whose RBF was evaluated by the ${ }^{133} \mathrm{Xe}$ method. In the adults, repeated studies were not performed in the same subject and groups of patients were compared. Only $40 \mathrm{ml}$ contrast medium was injected into the descending aorta and, although the weights of the patients were not given, it can be assumed that the dose of contrast was less than $1 \mathrm{ml} / \mathrm{kg}$, a dose much less than that given to our patients. In the adult group studied before angiography, blood flow and fractional flow were similar to that obtained in the group examined 30-120 min after angiography [27]. Our repeat studies were performed within 30 min.

A number of possible explanations can be offered to explain why children respond differently than adults. If angiocardiography increases catecholamine release, the kidney of the child may, like that of the developing puppy [30], be more likely to respond with decreasing RBF. If the renin angiotensin system is responsible for the vasoconstriction after angiography, the quantity of renin available in the kidney to induce the vasoconstrictor response may be greater in the patients with CHD. Plasma renin activity is increased in normal neonates [36].

Moreover, the child undergoing cardiac catheterization receives more contrast medium per unit of body weight than the adult. As the glomerular filtration rate is less in children than adults, injected contrast media would remain in the extracellular space for a proportionately longer time. The increase in serum osmolality after injection is associated with expansion of the vascular compartment [35], a drop in serum oncotic pressure and hematocrit [15], an osmotic diuresis [14], and often an increase in blood pressure. These five changes have been shown to decrease proximal 
tubular sodium reabsorption and to increase distal tubular sodium delivery which may increase local renin release. Perhaps the duration of the increase in renin release determines the period of time of vascular vasoconstriction.

\section{Summary}

Thirty measurements of renal blood flow and its intrarenal distribution were made in 20 children ranging in age from $16 / 12$ to $10 \% / 12$ years. In kidneys considered to be normal, average flow through outer and inner cortex and fractional flow were similar to those found in adults. Children with CHD were shown to have reduced outer cortical flow. After angiography, a significant fall in outer cortical flow occurred.

\section{References and Notes}

1. Alleyne, G. A. O.: The effect of severe protein calorie malnutrition on the renal function of Jamaican children. Pediatrics, 39: 400 (1967).

2. Barnett, H. L., AND Vesterdal, J.: The physiologic and clinical significance of immaturity of kidney function in young infants. J. Pediat., 42: 99 (1953).

3. Blaufox, M. D., Fromowitz, A., Gruskin, A., Meng, C.-H., AND ElKIN, M.: Validation of use of xenon 133 to measure intrarenal distribution of blood flow. Amer. $J$. Physiol., 219: 440 (1970).

4. Brown, A. K., Epstein, E. J., Coulshed, N., Clarke, J. M., AND Doukas, N. G.: Haemodynamic changes after angiocardiography. Brit. Heart J., 31: 233 (1969).

5. Calcagno, P. L., and Rubin, M. I.: Renal extraction of para-amino-hippurate infants and children. J. Clin. Invest., 42: $1632(1963)$

6. Caldicott, W. J. H., Hollenberg, N. K., and Abrams, H. L.: Characteristics of response of renal vascular bed to contrast media: Evidence for vasoconstriction induced by renin-angiotensin system. Invest. Radiol., 5: 539 (1970).

7. CARriere, S.: Effect of norepinephrine, isoproterenol, and adrenergic blockers upon the intrarenal distribution of blood flow. J. Physiol. Pharmacol., 47: 199 (1969).

8. Carriere, S., ANd Biron, P.: Effect of angiotensin I on intrarenal blood flow distribution. Amer. J. Physiol., 219: 1642 (1970).

9. CARriere, S., AND Friborg, J.: Intrarenal blood flow and $\mathrm{PAH}$ extraction during angiotensin infusion. Amer. $J$. Physiol., 217: 1708 (1969).

10. Cheek, D. B., And Graystone, J. E.: Growth and sympathetic activity. In: D. B. Cheek: Human Growth, p. 287 (Lea and Febiger, Philadelphia, 1968).

11. Chidsey, C. A., Braunwald, E., and Morrow, A. G.: Catecholamine excretion and cardiac stores of norepinephrine in congestive heart failure. Amer. J. Med., 39: 442 (1965).

12. Cohen, L. S., Kokko, J. P., and Williams, W. H.: Hemolysis and hemoglobinuria following angiography. Radiology, 92: 329 (1969).
13. Dell, R. B., Sciacca, R., Lieberman, K., Case, D. B., and CANnon, P. J.: A weighted least square technique for the kinetic data and its application to the study of renal ${ }^{133}$ xenon washout in dogs and man. Circ. Res., 32: 71 (1973).

14. Dirks, J. H., Cirksena, W. J., AND Berliner, R. W.: Micropuncture study of the effect of various diuretics on sodium reabsorption by the proximal tubules of the dog. J. Clin. Invest., 45: 1875 (1966).

15. EARLY, L. E., AND FrIEDler, R. M.: The effects of combined renal vasodilatation and pressor agents on renal hemodynamics and the tubular reabsorption of sodium. J. Clin. Invest., 45: 542 (1966).

16. Edelmann, C. M., JR., AND Wolfish, N. M.: Dietary influence on renal maturation in premataure infants (Abstract), p. 7 (Society for Pediatric Research, May 1968).

17. Eliakim, M., Stern, S., ANd Nathan, H.: Site of action of hypertonic saline in the pulmonary circulation. Circ. Res., 9: 327 (1961).

18. Fluck, D. C., Evans, T. R., Siggers, D. C., Crawley, J., AND SRIVongse, S. A.: Distribution of renal blood flow in patients with heart disease. Clin. Sci., 42: 637 (1972).

19. Gootman, N., Rudolph, A. M., and Buckley, N. M.: Effects of angiographic contrast media on cardiac function. Amer. J. Cardiol., 25: 59 (1970).

20. Grainger, R. G.: Renal toxicity of radiological contrast media. Brit. Med. Bull., 28: 191 (1972).

21. Gruskin, A. B., Auerbach, V. H., and Black, I. S.: Plasma renin activity in congenital heart disease (unpublished observations)

22. Gruskin, A. B., Edelmann, C. M., JR., and Yuan, S. Maturational changes in renal blood flow in piglets. Pediat. Res., 4: 7, 1970.

23. Gruskin, A. B., Oetliker, O., Wolfish, N. M., Gootman, N., AND Edelmann, C. M., JR.: Effects of angiography on renal function anad histology in infants and children. J. Pediat., 76: 41 (1970).

24. Gustowska, X., Lendrum, B. L., Cantez, T., and Caronel, A.: Renal hemodynamics in congenital heart disease in children. Circulation, 33 (suppl. III): 118 (1966).

25. Hollenderg, N. K., Epstein, M., BAsch, R. I., AND MERRILL, J. P.: "No Man's Land" of the renal vasculature. An arteriographic and hemodynamic assessment of the interlobar and arcuate arteries in essential and accelerated hypertension. Amer. J. Med., 47: 845 (1969).

26. Hollenberg, N. K., Epstein, M., Basch, R. O., Merrill, J. P., AND HICKLER, R. B.: Renin secretion in the patient with hypertension: relationship to intrarenal blood flow distribution. Circ. Res., 34 (supplement I): 113 (1969).

27. Hollenberg, N. K., Rosen, S. M., O'Connor, J. F., PotChen, E. J., Basch, R., Dealy, J. B., JR., and Merrill, J. P.: Effect of aortography on renal hemodynamics in normal man. Invest. Radiol., 3: 92 (1968).

28. Hollenberg, N. K., Solomon, H. S., Adams, D. F., Abrams, H. L., AND MERRILL, J. P.: Renal vascular responses to angiotensin and norepinephrine in normal man. Circ. Res., 31: 750 (1972).

29. Jose, P. A., Logan, A. G., Slotkoff, L. M., Lilienfield, L. S., Calcagno, P. L., AND EISNER, G. M.: Intrarenal blood flow distribution in canine puppies. Pediat. Res., 5: 335 (1971).

30. Jose, P., Slotkoff, L., Lilienfield, L., Calcagno, P., and 
EISNER, G.: Catecholamines and renal blood flow in the puppy. Clin. Res., 21:76 (1973).

31. Kilcoyne, M. M., AND Cannon, P. J.: Influence of thoracic caval occlusion on intrarenal blood flow distribution and sodium excretion. Amer. J. Physiol., 220: 1220 (1971).

32. Kilcoyne, M. M., ANd Cannon, P. J.: Neural and humoral influences on intrarenal blood flow distribution during thoracic caval occlusion. Amer. J. Physiol., 220: 1231 (1971).

33. KIRKLand, J. A., AND Haslock, M. R.: Transient proteinuria: Following intravascular injection of contrast media. Lancet, i: 693 (1961).

34. Kloster, F. E., Friesen, W. G., Green, G. S., and Judkins, M. P.: Effects of coronary arteriography on myocardial blood flow. Circulation, 46: 438 (1972).

35. Know, F. G., Howards, S. S., Wright, F. S., Davis, B. B., AND BERLINER, R. W.: Effect of dilution and expansion of blood volume on proximal sodium reabsorption. Amer. J. Physiol., 215: 1041 (1968).

36. Kotchen, T. A., Strickland, A. L., Rice, T. W., AND WALters, D. R.: A study of the renin-angiotensin system in newborn infants. J. Pediat., 80: 938 (1972).

37. KrovetZ, L. J., AND GoldBloom, S.: Normal standards for cardiovascular data. Examination of the validity of cardiac index. Johns Hopkins Med. J., 130: 174 (1972).

38. Krovetz, L. J., Simon, A. L., Levy, R. J., and Tift, W.: Effects of angiocardiographic contrast media on cardiac function. Amer. J. Cardiol., 25: 59 (1970).

39. LADEFOGED, J.: Measurements of the renal blood flow in man with the ${ }^{133}$ xenon washout technique. Scand. J. Clin. Lab. Invest., 18: 299 (1966).

40. Lendrum, B. L., Miller, R. A., and Hastreiter, A. R.: Renal PAH extraction in children with congenital heart disease. Circulation, 33-34 (suppl. III): 155 (1966).

41. Matsuyama, S., Mayashi, M., and Takatada, M.: Renal clearance tests of various congenital heart diseases in childhood. Acta Paediat., 7: 45 (1965).

42. Metrizi, A. ND Drash, A.: Growth disturbance in congenital heart disease. J. Pediat., 61: 418 (1962).

43. Pinsker, K. L., Lewy, J. E., and Braudo, J. L.: The effects of angiocardiography on renal function and fluid and electrolyte balance. Chicago Med. Sch. Quart., 28: 1 (1969).

44. Potter, D., Jarrah, A., Sakai, T., Harrah, J., and HolliDAY, M. A.: Character of function and size in kidney during normal growth of rats. Pediat. Res., 3: 51 (1969).

45. Rainey, R. L., KNox, G. F., and Culbertson, J. W.: Renal and general hemodynamic findings in cyanotic congenital heart disease. Circulation, 29-30 (suppl. III): 142 (1964).

46. Rainey, R. L., Know, G. E., And Culbertson, J. W.: Renal hemodynamics in acyanotic congenital heart disorders at ten to twenty-two months following surgical correction. Circulation, 29-30 (suppl. III): 142 (1964).

47. Riggs, D. S.: Mathematical Approach to Physiological Problems (The William \& Wilkins Co., Baltimore, 1963).

48. Rosen, S. M., HollenberG, N. K., Dealy, J. B., JR., and
MerriLl, J. P.: Measurement of the distribution of blood flow in the human kidney using the intra-arterial injection of ${ }^{133} \mathrm{Xe}$ : Relationship to function in the normal and transplanted kidney. Clin. Sci., 34: 287 (1968).

49. SOLOMON, S., AND CAPEK, K.: Increased food availability and renal development of neonatal rats. Biol. Neonate, 21: 9 (1972).

50. SPEAR, G. S.: The glomerulus in cyanotic congenital heart disease and primary pulmonary hypertension. Nephron, 1: 238 (1964).

51. Spear, G. S., and Kihara, I.: The glomerulus in cyanotic congenital heart disease: An immunofluorescent study. Bull. Johns Hopkins Hosp., 115: 481 (1964).

52. Spear, G. S., AND Vitsky, B. H.: Hyalinization of afferent and efferent glomerular arterioles in cyanotic congenital heart disease. Amer. J. Med., 41: 309 (1966).

53. Strong, W. B., Botti, R. E., Srlbert, D. R., and Liebman, J.: Peripheral and renal vein plasma renin activity in coarctation of the artery. Pediatrics, 45: 254 (1970).

54. Thorburn, G. D., Kopals, H. H., Herd, J. A., Hollenberg, M., O'Morchoe, C. C. C., AND Barger, A. C.: Intrarenal distribution of nutrient blood flow determined with krypton ${ }^{85}$ in the unanesthetized dog. Circ. Res., 13: 290 (1963).

55. Thurau, K., and Levine, D. Z.: The renal circulation. In: C. Rouiller and A. F. Muller: The Kidney, Morphology, Biochemistry, Physiology, Vol. III, p. 12 (Academic Press, New York, 1971).

56. Watanabe, T., and Tanaka, K.: Renal changes in cyanotic congenital heart disease. Jap. Circ. J., 33: 313 (1969).

57. Windhager, E. E., Lewy, J. E., AND Spitzer, A.: Intrarenal control of proximal tubular reabsorption of sodium and water. Nephron, 6: 247 (1969).

58. Young, D. B., AND Rostofer, H. H.: Effect of acute changes in plasma osmolality on renin release. Fed. Proc., 32: 379 (1973).

59. Zeman, F. J.: Effect of protein restriction on the kidney of the newborn young of rats. J. Nutr., 94: 111 (1968).

60. Packard Instrument Co., Downers Grove, Ill.

61. Cipher Data Products Corporation, San Diego, Calif.

62. Ampex Corporation, Redwood City, Calif.

63. Hewlett-Packard, Palo Alto, Calif.

64. We wish to thank Suzanne Brickley and Paul Berube for their technical assistance, Victor C. Vaughan III for reviewing the manuscript, and Mr. John Whitney of Cipher Data, San Diego, California for modifying the magnetic tape to fit our system.

65. This research was supported in part by grants from the National Institutes of Health (HE 12651), General Clinical Research Center (RR-75), General Research Support (RR5624), and the Eye Fund of St. Christopher's Hospital for Children.

66. Requests for reprints should be addressed to: A. B. GrUSKIN, M.D., St. Christopher's Hospital for Children, 2600 N. Lawrence St., Philadelphia, Penn. 19133 (USA).

67. Accepted for publication January 8, 1974. 